Waynn-Nielsen C. Destriza, MD

Roderick B. De Castro, MD

Howard M. Enriquez, MD

Department of Otolaryngology Head and Neck Surgery Ospital ng Makati
Correspondence: Dr. Howard M. Enriquez

Department of Otolaryngology Head and Neck Surgery 5th Floor, Ospital ng Makati

Sampaguita Street, Brgy. Pembo, Makati City 1208

Philippines

Phone: (632) 8826316 local 309

Email: osmakenthns@yahoo.com

Reprints will not be available from the authors.

The authors declared that this represents original material that is not being considered for publication or has not been published or accepted for publication elsewhere, in full or in part, in print or electronic media; that the manuscript has been read and approved by all the authors, that the requirements for authorship have been met by each author, and that each author believes that the manuscript represents honest work.

Disclosures: The authors signed disclosures that there are no financial or other (including personal) relationships, intellectual passion, political or religious beliefs, and institutional affiliations that might lead to a conflict of interest.

\section{An Experimental Study on Maximum Sound Output Capabilities and Preferred Listening Levels Using Different Earphone Types}

\begin{abstract}
Objective: The study aims to compare the maximum sound output capabilities of different earphone types/music style combinations. The study also intends to assess the preferred listening levels (PLL) of test subjects using different earphone types with background noise accession. The study also seeks to determine the presence or absence of a threshold shift on headphone/music style combination PLLs that exceed the recommended noise limit.
\end{abstract}

\section{Methods:}

Design: Experimental Study

Setting: Tertiary Government Hospital

Subjects: Thirty (30) hearing healthy volunteers were sampled from hospital staff aged 18-40 years with no known history of ear pathology and/or use of any known ototoxic drugs, with normal otoscopy, audiograms of less than $20 \mathrm{~dB}$ from $125 \mathrm{~Hz}$ to $8000 \mathrm{~Hz}$ and no exposure to loud noise from any source within the previous three days.

The sound pressure levels (SPL) delivered by three (3) types of earphones (earbud type, in-ear type, supra-aural type) were measured at maximum volume setting of a personal media player (iPod, Apple Inc.), while playing different music genres. The test subjects were asked to listen at their preferred listening levels (PLL) using the different types of earphones at increasing background noise accession.

Results: The earbud type averaged the greatest SPL among the earphone types and pop music averaged the greatest SPL among the music styles. Comparison of the maximum output capabilities revealed that there was a significant difference among different brands of earphones of the same type. However, no significant difference were found among songs of similar music style and across different music styles in all earphones except the in-ear type. PLL average was at $90.4 \mathrm{~dB}$ in a silent environment with increasing intensity as background noise accentuated. Supra-aural earphones registered the least increase in PLL in a loud environment due to its higher background noise-attenuating capabilities.

Conclusion: Having a significant difference among earphone types with regard their maximum output capabilities, it is recommended to check the specifications of the earphone type one intends to use. In using personal media players (PMP), the volume should be set at the lowest comfortable level. While choice of music style remains the discretion of the listener, the choice of music style should be considered for long periods of listening. Because the PLL of test 
ORIGINAL ARTICLES

subjects were alarmingly high, the authors recommend intervention in their listening habits. Background noise attenuating capabilities of earphones play a factor in reducing excessive sound energy from reaching the ear reducing the PLL and decreasing the risk for noiseinduced hearing loss.

Keywords: earphones, music styles, personal media players, preferred listening levels, recreational noise, noise-induced hearing loss

Sound is a sensory perception and noise is commonly designated as an undesirable sound. However, this meaning may be obscured by subjective opinions - especially in this day and age when loud sounds may be desirable for some - we clinically define noise as any excessively loud sound that has potential harm to hearing. ${ }^{1}$ Noise-induced hearing loss (NIHL) is the second most common type of hearing loss next only to age-related hearing loss. NIHL has been well studied in the past decades and a relationship with noise exposure from occupational environment has been established. Since then, noise regulations in workplaces have been legislated to prevent NIHL. With the passage of time, the age of noisy factories has been reduced and we enter a new, digital age. Machines have been replaced by computers and the risk of NIHL from occupational noise has tremendously fallen. However, a new noise risk emerges from this evolution of mankind, recreational noise.

Recreational noise is the term for noise exposure during leisure hours which includes but is not limited to noise from clubs or discos, concerts, orchestra, cinema, television and personal media players (PMP). In comparison to occupational noise, recreational noise is more difficult to quantify because the intensity of sound is user dependent and there is no definite amount of time exposure. Hence, no local regulation has been imposed on recreational noise giving it a greater risk for NIHL. Of alarming concern among recreational noise sources are PMPs which have been widely available to the public with the advent of the iPod (Apple, Inc.). Because of this, a greater number of the population is exposed with no knowledge of its potential risk for NIHL. Moreover, the age of individuals with free access to PMPs has been getting younger and younger.

This study aims to compare the maximum sound output capabilities of different earphone types /music style combinations. The study also intends to assess the preferred listening levels of test subjects using different earphone types with background noise accession. The study also sought to determine the presence or absence of a threshold shift on headphone/music style combination PLLs that exceed the recommended noise limit. Assessment and analysis of the results may help outline recommendations to prevent noise-induced hearing loss and guidelines for safe use of personal media players.

\section{METHODS}

This was an experimental study on maximal output capabilities of three (3) types of earphones (earbud type, in-ear type and supraaural type) using an iPodTouch 4th generation MC008ZP (Apple, Inc., California, USA) as the sound source across five music styles (pop, country, hiphop, R\&B and rock). Three (3) earphone models/brands of each earphone type (Table 1) and five (5) songs of each music style (based on the top 5 songs of www.billboard.com, see (Table 2) were used in the experiment. The study was approved by our Institutional Ethical Review Board and divided in two phases. The first phase

Table 1. Earphone Types and Models $s^{\mathrm{a}}$

\begin{tabular}{|c|c|c|}
\hline Earphone Type & Model & Description \\
\hline Earbud Type (A) & CDR-King EP-030-V & $\begin{array}{l}\text { Speaker: } \varnothing 10 \mathrm{~mm} \text {, Impedance: } \\
32 \Omega \text {, Frequency: } 18-20000 \mathrm{~Hz} \text {, } \\
\text { Sensitivity: } 108 \mathrm{~dB} \pm 3 \mathrm{~dB}\end{array}$ \\
\hline Earbud Type (B) & iPod MPN: MA662G/B & $\begin{array}{l}\text { Impedance: } 32 \Omega \text {, Frequency: } \\
20-20000 \mathrm{~Hz}\end{array}$ \\
\hline Earbud Type (C) & Philips SHE2670 GN/98 & 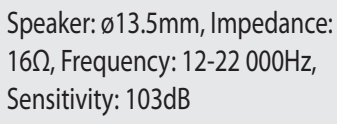 \\
\hline In-EarType (A) & CDR-King EB-101-LC & $\begin{array}{l}\text { Speaker: } \varnothing 9.5 \mathrm{~mm}, \text { Impedance: } \\
32 \Omega \text {, Frequency: } 10-20000 \mathrm{~Hz} \text {, } \\
\text { Sensitivity: } 115 \mathrm{~dB} \pm 3 \mathrm{~dB}\end{array}$ \\
\hline In-Ear Type (B) & Philips SHE3570GN/98 & $\begin{array}{l}\text { Impedance: } 16 \Omega \text {, Frequency: } \\
12-23500 \mathrm{~Hz} \text {, Sensitivity: } 102 \mathrm{~dB}\end{array}$ \\
\hline In-Ear Type (C) & Sennheiser CX270 & $\begin{array}{l}\text { Impedance: } 16 \Omega \text {, Frequency: } \\
19-20000 \mathrm{~Hz}\end{array}$ \\
\hline Supra-aural Type( A) & CDR-King HP-060-LA & $\begin{array}{l}\text { Speaker: } \varnothing 30 \mathrm{~mm} \text {, Impedance: } \\
32 \Omega \text {, Frequency: } 20-20000 \mathrm{~Hz} \text {, } \\
\text { Sensitivity: } 108 \mathrm{~dB} \pm 3 \mathrm{~dB}\end{array}$ \\
\hline Supra-aural Type (B) & Sennheiser HD201 & $\begin{array}{l}\text { Impedance: } 24 \Omega \text {, Frequency: } \\
21-18000 \mathrm{~Hz}\end{array}$ \\
\hline Supra-aural Type (C) & Philips SHL3100/00 & $\begin{array}{l}\text { Impedance: } 32 \Omega \text {, Frequency: } \\
18-20000 \mathrm{~Hz} \text {, Sensitivity: } 107 \mathrm{~dB}\end{array}$ \\
\hline
\end{tabular}

${ }^{\mathrm{a}}$ All earphones were wired and with no sound cancelling function

determined the A-weighted sound pressure level (SPL-A) delivered by each earphone/music style combination to a sound level meter (Extech Instruments Digital Sound Level Meter, Model 407768; frequency bandwidth: $31.5 \mathrm{~Hz}$ to $8 \mathrm{kHz}$, applicable standards: ANSI S1.4 1983 Type 2, IEC 61672 Class 2, CE). An artificial ear construct was built that held the sound level meter on one side and the earphone on the opposite side. The distance between the sound level meter and the earphone was approximately $2 \mathrm{~cm}$ to simulate the relationship of the earphone to the tympanic membrane. The construct was made of foam moulding allowing the earphones to fit snugly into the device and minimizing 


\section{ORIGINAL ARTICLES}

Table 2. Songs per Music Style

\begin{tabular}{|c|c|c|}
\hline Music Style & Song Title & Song Artist \\
\hline \multirow{5}{*}{ Country } & I Want Crazy & Hunter Hayes \\
\hline & Highway Don't Care & Tim McGraw feat. Taylor Swift \\
\hline & Wagon Wheel & Darius Rucker \\
\hline & Boys'Round Here & $\begin{array}{l}\text { Blake Shelton feat. Pistol Annies } \\
\text { \& Friends }\end{array}$ \\
\hline & Cruise & Florida Georgia Line \\
\hline \multirow{5}{*}{ HipHop } & U.O.E.N.O & Rocko feat. Future and Rick Ross \\
\hline & Feel This Moment & Pitbull feat. Christina Aguilera \\
\hline & Bad & Wale feat. Tiara Thomas \\
\hline & Power Trip & J. Cole feat. Miguel \\
\hline & Thrift Shop & $\begin{array}{l}\text { Macklemore and Ryan Lewis feat. } \\
\text { Wanz }\end{array}$ \\
\hline \multirow{5}{*}{$R \& B$} & Fine China & Chris Brown \\
\hline & Suit and Tie & Justin Timberlake feat. Jay Z \\
\hline & Body Party & Ciara \\
\hline & \#Beautiful & Mariah Carey feat. Miguel \\
\hline & Blurred Lines & $\begin{array}{l}\text { Robin Thicke feat. T.I. and Pharrell } \\
\text { Williams }\end{array}$ \\
\hline \multirow{5}{*}{ Pop } & Can't Hold Us & $\begin{array}{l}\text { Macklemore and Ryan Lewis feat. } \\
\text { Ray Dalton }\end{array}$ \\
\hline & Come and Get It & Selena Gomez \\
\hline & Just Give Me a Reason & Pink feat. Nate Ruess \\
\hline & I Love It & Icona Pop \\
\hline & Get Lucky & Daft Punk feat. Pharrell Williams \\
\hline \multirow{5}{*}{ Rock } & Lego House & Ed Sheeran \\
\hline & Sail & Awoination \\
\hline & Gone, Gone, Gone & Phillip Phillips \\
\hline & Ho Hey & The Lumineers \\
\hline & $\begin{array}{l}\text { My Songs Know What } \\
\text { You Did in the Dark } \\
\text { (Light'Em Up) }\end{array}$ & Fall Out Boy \\
\hline
\end{tabular}

the outside noise approximating the fit in a normal-hearing ear. (Figure 1) All experiments were done inside a sound treated booth. The sound source was at full battery and plugged to an electric outlet at all times during the experiment. Set at maximum volume setting the SPL delivered by each model of each earphone type was recorded while playing the song samples from each music style. This was to determine the maximum output capabilities of each earphone model of each earphone type. Data was gathered using the Extech Instruments bundled data acquisition software (Model $407768 \mathrm{v} .0509 \mathrm{~A}$ ) at a reading rate of 2 seconds.
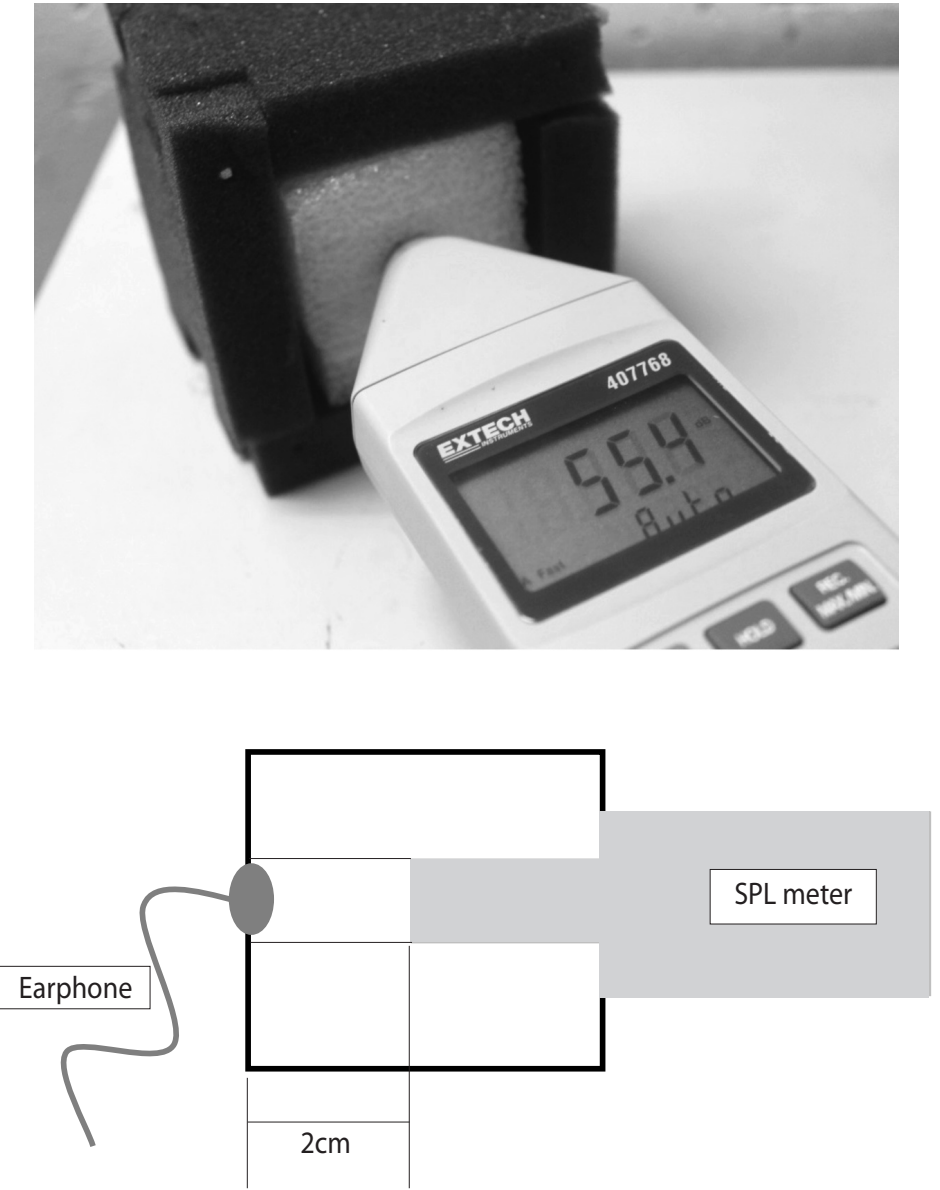

Figure 1. Pictures of the SPL Meter and Ear construct with Schematic Diagram of the Ear Construct

The second phase included thirty (30) hearing healthy volunteers aged 18-40 years old gathered from hospital staff and employees from whom informed consent was obtained. Participants had no known history of ear disease and no pathologic findings on otoscopy. An audiogram of $<20 \mathrm{~dB}$ from $125 \mathrm{~Hz}$ to $8000 \mathrm{~Hz}$ frequency had to be obtained to ensure normal hearing in all volunteers. Pregnant women and those taking any ototoxic drugs were excluded from the study. Participants were advised to avoid exposure to loud noise either from work or other recreational activities (clubbing, concerts, etc.) three (3) days prior to the test. Participants gave written informed consent and were asked to fill out and answer a set questionnaire for demographics and information on their habits using PMPs. One model/brand of each earphone type was chosen and one song among the music samples was chosen based on which gave the least variance of sound pressure throughout the duration of the song and least difference from the whole sample's sound pressure mean. The subjects underwent baseline audiometry prior to the experiment. Using an earphone splitter, one set 
ORIGINAL ARTICLES

of earphones was fitted by the patient and the other set of the same type and model fitted to the ear construct. The PMPs initial volume was set at 50\% and could be adjusted by the subject to his or her preferred listening level. The first round was recorded with no background noise although having an SPL average of around 44dBA. Using loudspeakers surrounding the participant, speech background noise was introduced into the room from another sound source at 50\% volume setting delivering a free field SPL of around $70 \mathrm{dBA}$ and preferred listening
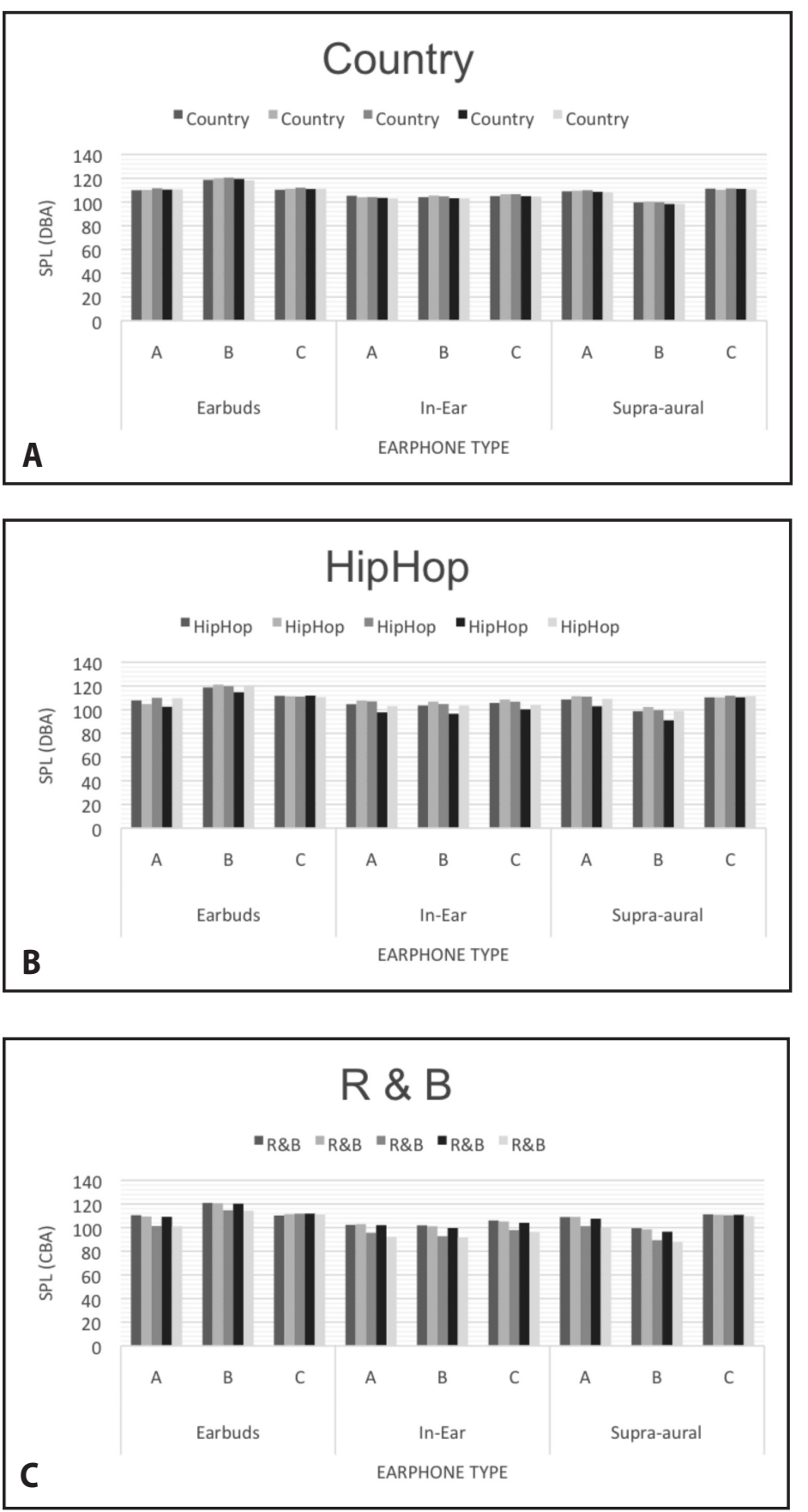

levels with background noise accession were recorded. After amplifying the background noise at $75 \%$ volume setting delivering a free field SPL of around $85 \mathrm{dBA}$, another recording was made. Sound pressure levels registered by the patients preferred volume setting were recorded using each type of earphones. A post-test audiometry was done to determine any threshold shift.

Data was gathered and analysed using the Extech Instruments bundled data acquisition software, Microsoft Excel 2013 (Microsoft
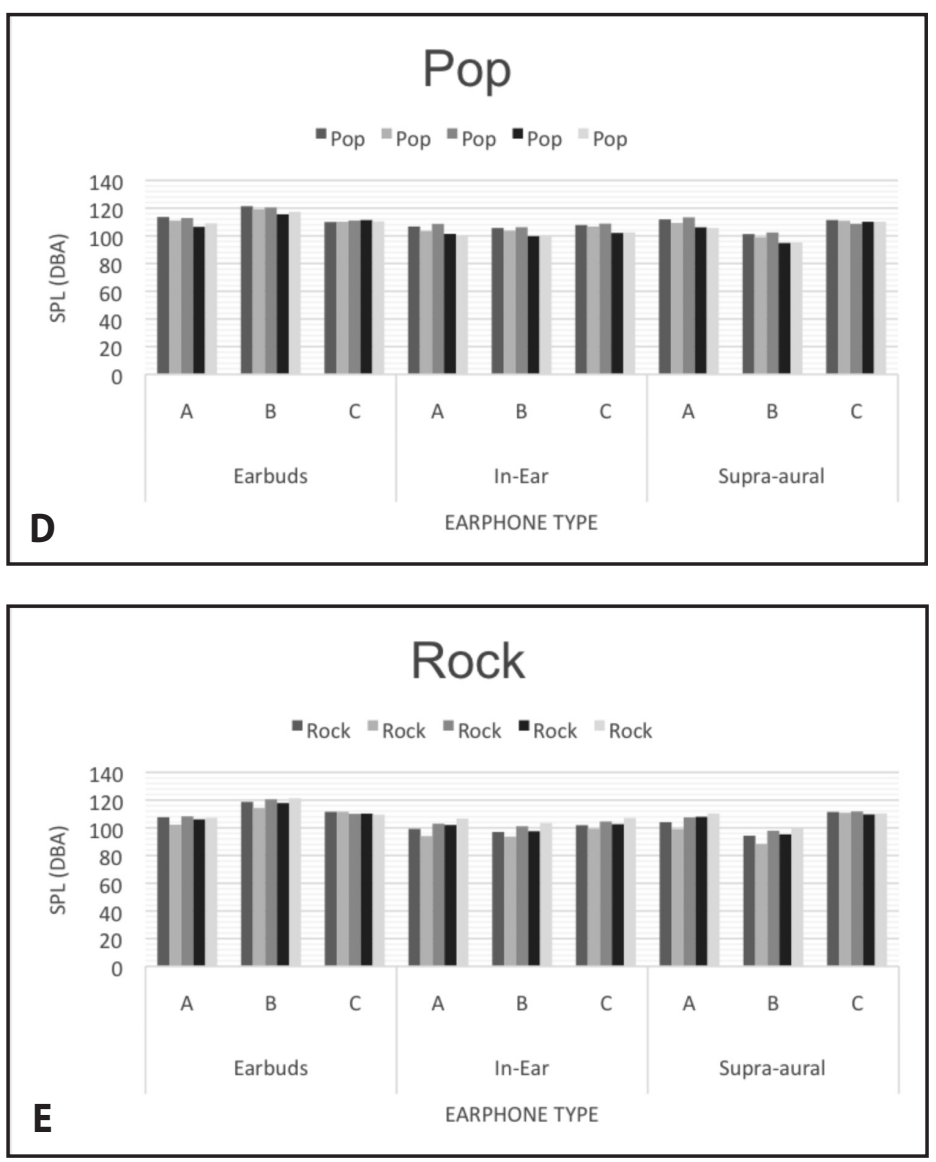

Figure 2 A-E. Comparison of Mean SPL of songs per music style delivered by each earphone model of each earphone type

Corporation, Redmond, Washington) and SPSS version 20 (SPSS, Inc., Chicago). All data was tested for normality of distrubution using Kolmogorov-Smirnov (KS) test for normality (for phase 1 subgroups, earbud type $p=0.20$, in-ear type $p=0.83$, supra-aural type $p=0.16$ and phase 2 subgroups, earbud type $p=0.20$, in-ear type 0.20 , supra-aural type $\mathrm{p}=0.16$ ) and Levene's test for homoscedasticity (phase 1 subgroups $p=0.497$ and phase 2 subgroups $p=0.595$ ), thus, parametric tests were preferred. 


\section{RESULTS}

The first phase of the experiment recorded the SPL delivered by each earphone type using different music styles at maximal volume setting. The earbud-type earphone playing a rock music style delivered the greatest intensity at $126.1 \mathrm{dBA}$.

The mean SPL delivered by a model/brand of earphone type using five songs of similar music style is depicted in Figure 2A-E. Comparison of mean SPL delivered by each earphone type of songs using a similar music style revealed no significant difference in both earbud type and supra-aural type of earphones. However in-ear earphones revealed a significant difference of SPL among all songs of similar music style (hiphop $p=2.42 E-05, R \& B \quad p=0.000755$, pop $p=0.000267$ and rock $p=0.005951)$ except country music $(p=0.199)$. It was found that there was a significant difference in the SPL delivered among the different models ( $A, B$ and $C$ ) of similar earphone type (Figure 3). This finding was constant in all earphone type/music style combinations except for two songs in the country style music $(p=0.045$ and $p=0.08$ ) using in-ear type of earphone.

Among the earphone types the earbud type delivered the greatest intensity of sound (112dBA). However, the mean SPL of all earphone models per earphone type set against the different music styles (Figure 4) revealed no significant difference among earphone type (earbud, inear and supra-aural types) in all music styles. Moreover, the mean SPL of all songs in a similar music style set against the different earphone types revealed no significant difference among the songs of the same music style. Analysis of mean SPL per music style using different earphone models of the same earphone type revealed no significant difference in using earbud type and supra-aural type of earphones. However, using in-ear type of earphones revealed a significant difference when using different models of earphone even of the same type. Additionally, comparing the mean SPL per earphone type across music styles revealed no significant difference in what earphone type was used.

The second phase of the experiment recorded the preferred listening levels (PLL) of subjects using different types of earphones at different background attenuations. There were 30 participants, 12 males and 18 females aged 18 to 36 (mean age 26 years-old). Participants of the study were mostly female (60\%) aged $25-30$ years (50\%). All of them listened to a PMP (100\%); the most common was an iPhone (Apple, Inc.) using an in-ear type of earphone (83\%). Sixty-six percent (66\%) listened to PMP at least twice a week while $16 \%$ of the participants listened to it everyday. The most commonly preferred music style was R\&B music $(50 \%)$ and the usual volume setting fell around $75-99 \%$ (83\%). In terms of awareness, $66 \%$ of the participants believed that use of PMP can lead to hearing problems.

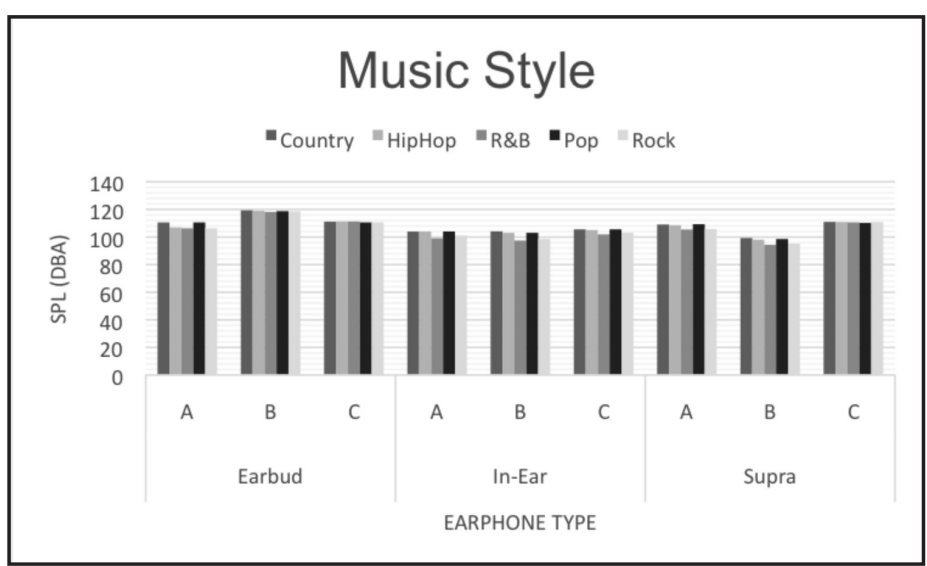

Figure 3. Comparison on Mean SPL of Different Music Styles per Earphone Model of each Earphone Type

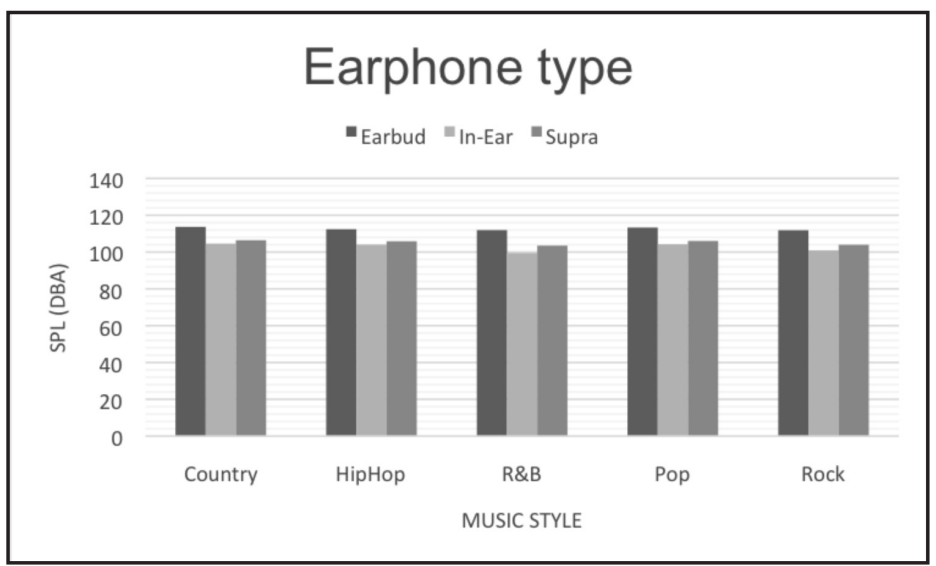

Figure 4. Comparison of the Mean SPL delivered by each earphone type using Different Music Styles

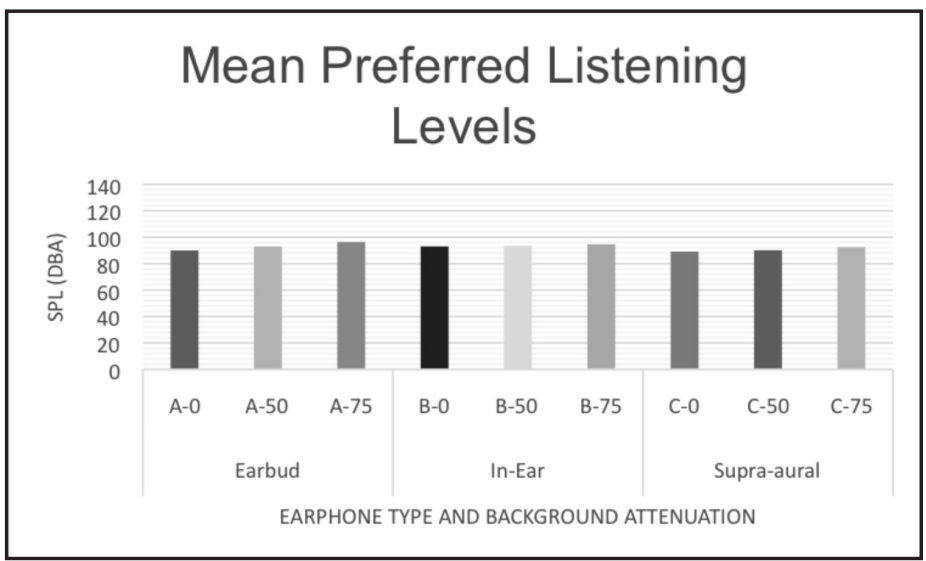

Figure 5. Comparison of Mean SPL at Preferred Listening Levels at Increasing Background Noise according to Earphone Type

There was a noted trend of increase in PLL with increasing background noise in all earphone types. (Figure 5) Using paired t-test analysis comparing the PLL from (1) no background noise to a background noise of $50 \%$ volume setting; (2) background noise of 50\% 


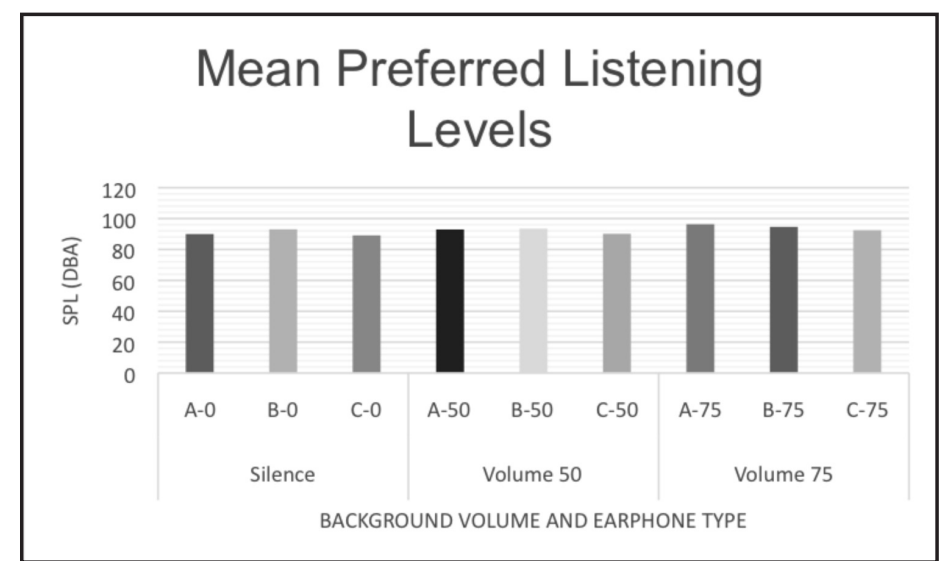

Figure 6. Comparison of Mean SPL at Preferred Listening Levels delivered by different earphone types grouped by background noise volume

volume setting to a $75 \%$ volume setting; and (3) no background noise to background noise of $75 \%$ volume setting, only the PLL while using the earbud type earphone revealed a statistically significant difference in comparison to $50 \%$ background volume setting to $75 \%$ background volume setting and no background noise to $75 \%$ background volume setting ( $p=0.004$ and $p=0.017$, respectively). The PLL of the other two types did not show any significant difference across the background volume settings. (Figure 6) Comparing the 3 earphone types on the same background volume setting revealed that the supra-aural type earphone registered the least PLL although it was not statistically significant (no background noise $\mathrm{p}=0.66 ; 50 \%$ background noise $p=0.75 ; 75 \%$ background noise $p=0.73$ ).

The post-experiment pure tone audiometry to find out if a threshold shift could be noted in the participants took about an hour each to complete with noted PLL going beyond 85dBA. Only seven percent (7\%) of the participants were noted to have a clinically significant threshold shift of beyond $10 \mathrm{~dB}$. The average threshold shift for the entire sample was a $3 \mathrm{~dB}$ shift.

\section{DISCUSSION}

Sound is quantified by its air vibrations measured in sound pressure levels $(L)$ measured on a logarithmic scale with units of decibels $(d B)$ to indicate the loudness of sound. The human ear is not equally sensitive to sound at different frequencies; thus a spectral sensitivity factor (A-filter) is used to weight the sound pressure level at different frequencies to account for the perceived loudness of sound. The A-weighted sound pressure is averaged over a period of time $(T)$ and is designated by LAeq, T (A common exposure period is 8 hours, hence the parameter is designated by the symbol LAeq,8h). ${ }^{2}$

Sound pressure levels delivered from earphones set at maximum volume setting can go higher than $125 \mathrm{dBA}$ which is in the range of a jet engine at $100 \mathrm{~m}(110-140 \mathrm{~dB}) .^{3}$ At this level, potential for hearing damage increases as the sound goes beyond $120 \mathrm{~dB}$ and is just below the threshold of pain which is $130 \mathrm{~dB} .{ }^{4}$ Repeated exposure at this range of SPL can harm the ear and lead to permanent threshold shift in hearing.

However, in reality few persons listen at maximum volume setting as listeners often adjust their volume setting to levels which they are most comfortable with-- hence, the study measured the preferred listening levels of test subjects. In a silent environment, $61 \%$ of our volunteers preferred to listen at $<90 \mathrm{~dB}$ intensity and the average PLL was $90.7 \mathrm{dBA}$. As expected, this further increased as the background noise became louder. The ear tries to differentiate among sound signal variations between the sound it wants to listen to (signal) in contrast to the unwanted sound (noise). This is commonly known as signal-noise relationship concept. ${ }^{5}$ Hence, to maintain this ratio (signal/noise) the psychoacoustic response to increasing background noise is to increase the PLL of the listener. This experiment simulates the environment wherein a listener is exposed to a noisy environment like public transport. In public transportation, noise can reach up to $80-90 \mathrm{~dB}$ in a traffic roadway and it is common for commuters to travel while listening to a PMP using their preferred earphones. The recommended noise dose in the Philippines is less than $90 \mathrm{~dB} \operatorname{SPL}(A)$ for 8 hours ${ }^{6}$ with the amount of time decreased by half every $3 \mathrm{~dB}$ increment excess noise level. Extrapolating our data at 75\% volume setting background noise $(\sim 85 \mathrm{~dB})$, the average PLL is at $94.5 \mathrm{dBA}$ and taking into consideration the travel time of approximately one hour, most of the listeners will exceed the set daily noise dose.

A major part of our knowledge about noise-induced hearing loss relates to occupational noise exposure. International standards recommended the equivalent sound pressure level (LAeq, 8h) of $85 \mathrm{~dB}(\mathrm{~A})$ as the exposure limit for occupational noise (ISO 1999:1990; NIOSH revised criteria 1998). ${ }^{7}$ In the Philippines, the Department of Labor and Employment (DOLE) issued Occupational Safety and Health (OSH) Standards stating that in an 8-hour work day the noise exposure should not exceed $90 \mathrm{~dB}(\mathrm{~A}) .^{6}$ Outside the workplace, a high risk of hearing impairment arises from participating in concerts and clubs using personal media players (PMP), exercising or attending noisy sports or from exposure to military noises. These exposures have been collectively termed recreational noise.

The first effects of exposure to excessive sound is a threshold shift. ${ }^{2}$ A threshold shift can either be a reversible damage known as Temporary Threshold Shift (TTS) or a permanent damage known as Permanent Threshold Shift (PTS) to the peripheral auditory end organ. ${ }^{1}$ 


\section{ORIGINAL ARTICLES}

The pathophysiology of TTS was correlated with a buckling of the supporting pillar cell bodies in the frequency region of the maximal exposure effect while PTS was consistently correlated with a focal loss of hair cells and a complete degeneration of the corresponding population of nerve fiber endings. ${ }^{8}$ The precise relationship between TTS and PTS stages of hearing loss caused by noise exposure is still unknown. ${ }^{1}$ Threshold shift is the precursor of noise-induced hearing loss (NIHL). The problem with this type of hearing loss is that the impairment is gradual, the affected individual will not notice changes in hearing ability until a large threshold shift has occurred. The impairment occurs predominantly at higher frequencies (3 to $6 \mathrm{kHz}$ frequencies) with the largest effect at $4 \mathrm{kHz}$ frequency. ${ }^{2}$ Hearing impairment was defined by the World Health Organization (WHO) in 2008 as hearing level with audiometric ISO value greater than $25 \mathrm{~dB}$ on the better ear. ${ }^{5}$

Global statistics show an increase in prevalence of this disease yearly, continually affecting the quality of life and productivity of majority of the general population. WHO estimates show that there were 250 million persons worldwide with disabling hearing impairment in 2000 comprising about $4.2 \%$ of the world's population. ${ }^{9}$ Two-thirds of the hearing impaired population come from developing countries such as Indonesia, India, Myanmar, Sri Lanka, Thailand and the Philippines. In the third national health and nutrition examination survey of 1988-1994 in the USA it was found that among children aged 6-19years, $12.5 \%$ had noise-induced threshold shift (NITS) in one or both ears, with higher prevalence in boys (14.2\%) compared to girls (10.1\%), and in older aged children 12-19 (15.5\%) compared to 6-11 years olds (8.5\%). ${ }^{9} \mathrm{~A}$ recent local study entitled The Philippine Disability Survey, listed the prevalence rate of disability at $2.9 \%$ covering a total sample population of $59,443 .{ }^{9}$ Out of the $2.9 \%$, hearing impairment ranked second comprising 33\% of all persons with disabilities. ${ }^{9}$ The National Statistics Office conducted a disability survey in 1995 registering 919,292 persons with disabilities (PWD), 115,375 persons (12\%) had hearing impairment. ${ }^{10}$ In 1997, according to the $\mathrm{DOH}$ National Registry, hearing impairment was said to have a prevalence rate of $17 \%$ out of 597,345 individuals with disabilities were listed in varying forms of hearing impairment. ${ }^{11}$

Among the music styles studied, pop and country music gave the highest intensity of sound (108dBA); however, choice of music style is of trivial importance only as it contradicts the purpose of listening to music if we choose to listen to a different music style just to reduce the risk. Music style choice should still be considered specially when planning to listen to PMP over long periods of time or at high intensities.

The supra-aural earphones averaged the least PLL at $75 \%$ background noise volume setting. This is expected due to the built of the earphone which covers the most of the area of the pinna, thus adding the earphone's background noise attenuation capability. Next was the in-ear type, which delivers the signal more directly than the other types, thus maintaining a higher signal-to-noise ratio, hence the lower PLL. Assuming that a lower PLL reflects a lower acoustic energy reaching the tympanic membrane, maintaining a high signal-to-noise ratio is of utmost importance in reducing the risk of NIHL. Therefore, proper selection of earphones which provides better quality or clarity (increased signal) and with good background noise attenuation (decreased noise) may be the most effective measure in risk reduction for NIHL due to recreational noise (PMP). Taking into consideration the model/brand of earphones, there is a significant difference when using different brands of earphones, hence the choice of earphone model is also of importance in reducing the risk of potential damage to the ear.

Bearing in mind the recommended daily noise dose and inferring our data from the SPL output findings, we estimated the time of exposure a person should listen to a distinct music style using a distinct earphone type at maximal volume setting. (Table 3) Additional data can be gathered using different volume settings but this was not included in this study. Future studies could further delineate the limits of time exposure with a distinct earphone type and music style to recommend legislation on guidelines for proper use of PMPs. These time exposures can be applied only in a silent environment which limits its use. The presence of background noise may shorten the computed time limit due to additional noise reaching the ear. Although the actual sound pressure that the reaches the ear in a silent environment is only $2-4 \mathrm{dBA}$ above the PLL estimation even in a loud environment with near 80 $85 \mathrm{dBA}$ of background noise, ${ }^{12}$ this minimal difference has to be taken in consideration. The attenuating capabilities of the earphone used also

Table 3. Personal Media Player Recommended Exposure Time for Safety,

\begin{tabular}{|c|c|c|c|c|c|c|c|c|c|c|c|c|c|c|c|}
\hline \multirow[b]{3}{*}{$100 \%$} & \multicolumn{3}{|c|}{ Country } & \multicolumn{3}{|c|}{ Pop } & \multicolumn{3}{|c|}{ Rock } & \multicolumn{3}{|c|}{ HipHop } & \multicolumn{3}{|c|}{$R \& B$} \\
\hline & Earbud & In-ear & Supra & Earbud & In-ear & Supra & Earbud & In-ear & Supra & Earbud & In-ear & Supra & Earbud & In-ear & Supra \\
\hline & 1.9 & 15 & 15 & 1.9 & 15 & 15 & 3.8 & 30 & 15 & 3.8 & 15 & 15 & 3.8 & 60 & 30 \\
\hline
\end{tabular}

Time is measured in minutes

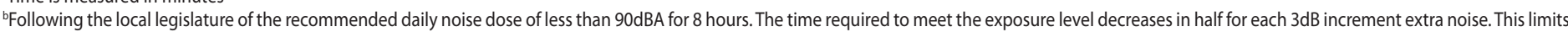
are only applicable in silent environment and may be lower in areas with background noise. 
affects the sound energy reaching the ear.

Summarizing our findings, we recommend using PMPs at the lowest comfortable volume possible. In selecting earphone types, a clearer signal output and higher background noise attenuation capability should be taken into consideration. Supra-aural earphones are recommended since they tend to have the highest background noise attenuation capabilities among earphone types. The brand/model of earphones among similar earphone types is also important since they have been shown to differ significantly. It is recommended to check the audio specifications (frequency response: $20-20 \mathrm{kHz}$, sensitivity: $92-110 \mathrm{~dB}$, lower impedance) of the earphone you intend to buy and use. Time limits of exposure should be further explored and setting of recommended guidelines for use of PMP should be initiated. However, maximal time exposure is not reliable in a loud environment and may depend on the background noise attenuation of the earphone. The recommendation of using noise attenuating or noise cancelling earphones are mainly based on the audiological data and findings on this study. Precautions should still be advised among listeners since background noise attenuation includes the dampening not only of noise but also of warning sounds and/or alarms such as approaching vehicles or fire alarms.

The authors hope that the study can awaken public awareness of the risk brought about by the increasing use of PMPs and initiate the development of guidelines and recommendations for proper use of PMPs, to lessen the risk for recreational NIHL at least in PMP usage.

\section{REFERENCES}

1. Lonsbury-Martin B, Martin G. Noise-Induced Hearing Loss. In: Flint PW, Haughey BH, Lund VJ, Richardson MA, Robbins KT, Thomas JR, et al. Cummings' Otolaryngology Head and Neck Surgery. $5^{\text {th }}$ Ed. 2010; 151:2140-2152.

2. Concha-Barrientos M, Campbell-Lendrum D, Steenland K. Occupational noise: assessing the burden of disease from work-related hearing impairment at national and local levels. Geneva, World Health Organization, 2004. (WHO Environmental Burden of Disease Series, No. 9).

3. Stevens SS, Warshofsky F and the Editors of Time-Life Books, Sound and Hearing, Life Science Library. Time-Life Books, Alexandria, VA, 1965. p. 173.

4. Nave CR. "Threshold of Pain". HyperPhysics. Scilinks. 2006. [Retrieved 2009 Jun 16]. Available from: http://hyperphysics.phy-astr.gsu.edu/hbase/hph.html\#hph

5. SCENHIR (Scientific Committee on Emerging and Newly Identified Health Risks). Scientific Opinion on the potential health risks of exposure to noise form personal music players and mobile phones including a music playing function. 2008 Sep 23 [cited 2013 May 12]. Available from: (http://ec.europa.eu/health/opinions/en/hearing-loss-personal-music-player-mp3)

6. Department of Labor and Employment, Philippines. Occupational Safety and Health Standards. Amended 1989. Intramuros, Manila: Occupational Safety and Health Center, Department of Labor and Employment; February 2005 - May 2013.

7. NIOSH. Criteria for a recommended standard: occupational noise exposure. Revised criteria 1998. Cincinnati, OH, National Institute for Occupational Safety and Health.

8. Nordmann AS, Bohne BA, Harding GW. Histopathological differences between temporary and permanent threshold shift. Hear Res. 2000 Jan; 139 (1-2):13-30.

9. Guzman CZ. The Philippine Disability Survey. In: Baltazar JP, Mancao BD, Baquilod MM, Trinidad FE. Strategic Planning Workshop on the National Ear and Hearing Health Care Program (2003 Mar 27-29, Manila, Philippines). 2003; p. 32.

10. Japan International Cooperative Agency, Planning and Evaluation Department. Country Profile on Disablity: Republic of the Philippines. March 2002. pp. 3-9. [cited 2015 Apr 30]. Available from: http://siteresources.worldbank.org/DISABILITY/Resources/Regions/East-Asia-Pacific/ JICA_Philippine.pdf.

11. Del Prado J, Martinez N, Ramos H. Prevalence of Hearing Impairment in the Philippines, "Philippine Statistics". 2005. p. 16 [cited 2015 Apr 30].Available from: http://www.bhphil.org/ downloads/prevalence_of_ear.pdf.

12. Breinbauer HA, Anabalon JL, Gutierrez D, Carcamo R, Olivares C, Caro J. Output capabilities of personal music players and assesment of preferred listening levels of test subjects: outlining recommendations for preventing music-induced hearing loss. Laryngoscope. 2012 Nov; 122 (11): $2549-2556$. 